\title{
Bilateral Modified Radical Neck Dissection
}

National Cancer Institute

\section{Source}

National Cancer Institute. Bilateral Modified Radical Neck Dissection. NCI Thesaurus. Code C148527.

A surgical procedure in which all the bilateral cervical lymph node groups of the neck are removed but the internal jugular veins, sternocleidomastoid muscles, and/or spinal accessory nerves are preserved. 